\title{
Etnodesenvolvimento e desenvolvimento local: contributos para um debate teórico
}

\author{
Ethnodevelopment and local development: contributions for theoretical \\ debate
}

Monique Medeiros 1

\section{Resumo}

O uso do termo Etnodesenvolvimento, até meados de 1990, esteve restrito a algumas lideranças indígenas, Organizações Não Governamentais e intelectuais interessados no tema, porém, com o passar do tempo, tornou-se parte integrante do vocabulário de um público mais diverso, passando até a destacar-se em agências governamentais. Ainda na década de 1990, este termo foi alentado por outro denominado Desenvolvimento Sustentável, o qual se tornou popular a partir de 1992, através da Conferência Rio 92 das Nações Unidas. Seu enfoque acabou por evidenciar novas desigualdades sociais e espaciais, fazendo com que o contexto local de estratégias e ações, tomadas por determinados atores sociais, passassem a receber maior importância. Dessa maneira, a ideia de Desenvolvimento Local ganha espaço nos mais variados discursos políticos e pesquisas científicas. Em meio a elucidações aqui expostas, chega-se à conclusão de que os pilares da perspectiva etnodesenvolvimento e desenvolvimento local ainda se encontram em dinâmica construção, o que abre distintas possibilidades de estudos sobre a aplicação prática e a construção teórica desses conceitos a cada momento.

Palavras-chave: autonomia; desenvolvimento sustentável; valorização sociocultural;

\section{Abstract}

The use of the term Ethnodevelopment, by mid-1990, was restricted to some indigenous leaders, NGOs and intellectuals interested in the topic, but over time became part of the vocabulary of a more diverse audience, going to prominence in government agencies. Even in the 1990s, this term was sustained by another one, named Sustainable Development, which became popular in 1992 through the 1992 Rio Conference of the United Nations. Its approach turned out to highlight new social and spatial inequalities, making that the local context of

I Engenheira Agrônoma; Mestranda em Desenvolvimento Rural no Programa de Pós-Graduação em Desenvolvimento Rural, PGDR - Universidade Federal do Rio Grande do Sul, UFRGS; Av. João Pessoa, 3I, Centro, CEP: 90.040-000, Porto Alegre, Rio Grande do Sul, Brasil; E-mail: mmedeiros@ymail.com

Recebido para publicação em 25/0I/20 II e aceito em 25/02/20 I I

\begin{tabular}{|c|c|c|}
\hline & Guarapuava (PR) & v.7 n.I \\
\hline
\end{tabular}

DOI:10.5777/ambiencia.2011.01.01rb 
strategies and actions taken by certain social actors have passed to receive greater importance. Thus, the idea of Local Development is gaining ground in various political speeches and scientific researches. Between the clarifications presented here, it reaches the conclusion that the pillars of local development perspective ethnodevelopment and local development still are in a dynamic construction that opens various possibilities for studies on the practical and theoretical construction of these concepts at every moment.

Key words: : autonomy; sustainable development; sociocultural value.

\section{Introdução}

Este registro refere-se a um apanhado de ideias, às quais está inerente uma tentativa de formular questionamentos bem como interpretar significados para os termos "Etnodesenvolvimento" e "Desenvolvimento Local”. Os temas aqui abordados estarão entrelaçados na forma de itens, os quais abarcarão os principais conceitos acerca dos temas propostos, bem como seus autores expoentes responsáveis pela apresentação dos conceitos e pelas críticas e/ou divergências em torno do assunto. Os itens encontram-se estruturados da seguinte forma: breve contextualização sobre o termo Etnodesenvolvimento (1), sucinto comentário sobre o Desenvolvimento Sustentável (2) e Desenvolvimento Local (3), Paralelismos e incongruências em Desenvolvimento Local, Sustentabilidade e Etnodesenvolvimento (4), e, concluindo, um espaço intitulado "Para saber mais sobre...”(5), cujo objetivo é trazer comentários sintéticos sobre uma proposta de literatura complementar aos temas gerais aqui abordados.

\section{Breve contextualização - 0 Etnodesenvolvimento}

O final da década de 70 compôs, no cenário brasileiro, um período em que se delinearam articulações presentes até hoje nos assuntos indigenista e indígena. Tais articulações transcorreram nos processos de substituição do Serviço de Proteção aos Índios (SPI) pela Fundação Nacional do Índio (FUNAI), em 1967, e sua significativa crescente participação, de abertura de estradas e em outras formas de penetração na região da Amazônia, em meados de 1969 sob o regime ditatorial militar em curso à época, e da maciça entrada de capitais internacionais financiando a ditadura e os interesses agroindustriais.

Em âmbito de maior abrangência, na América Latina, as críticas dos efeitos etnocidas das políticas desenvolvimentistas tiveram, durante a Reunião de Barbados, em 1971, e posteriormente em San José de Costa Rica na "Reunião de Peritos sobre Etnodesenvolvimento e Etnocídio na América Latina”, em dezembro de 1981, eventos especiais na formulação de propostas para um 'desenvolvimento alternativo'.

Este 'desenvolvimento alternativo' marcado pelos projetos de futuro próprios aos povos indígenas abriu espaço para o termo Etnodesenvolvimento, do qual Rodolfo Stavenhagen foi um dos principais formuladores, tornando-se uma das referências mais significativas no assunto juntamente com Guilhermo Bonfil Batalla.

Segundo Batalla apud Verdum (2002), o etnodesenvolvimento é um exercício da capacidade social dos povos indígenas para 
construir seu futuro, aproveitando suas experiências históricas e os recursos reais e potenciais de sua cultura, de acordo com projetos definidos segundo seus próprios valores e aspirações, isto é, a capacidade autônoma, de uma sociedade culturalmente diferenciada, para guiar seu desenvolvimento.

Stavenhagen apud Verdum (2002) aponta que o etnodesenvolvimento das populações indígenas significa completa revisão das políticas governamentais 'indigenistas' que têm sido adotadas pela maioria dos governos. Um novo tipo de movimento social indígena militante vem reivindicando a reafirmação dos valores culturais indígenas e uma reavaliação da posição dos índios na estrutura social.

Foi através da Constituição de 1988 que se deu o reconhecimento formal do direito à organização e à representação própria dos indígenas no Brasil, o que proporcionou o processo de auto-organização dessas sociedades e o surgimento e a multiplicação de entidades indígenas e sua articulação em redes e movimentos de abrangência regional, nacional e internacional.

Passado pouco mais de dez anos, verifica-se que o processo de organização e articulação indígena não parou de crescer, especialmente aquele com perspectiva de autonomia dos aparelhos do Estado brasileiro. Os dados preliminares de um levantamento em curso no âmbito dos PDPI indicam que, na Amazônia Legal, existem hoje aproximadamente 280 organizações indígenas com diferentes naturezas e níveis de abrangência: de professores, de mulheres, de estudantes, de uma comunidade local ou envolvendo vários povos (VERDUM,2006).

Pode-se afirmar que a emergência das entidades indígenas e o crescimento de seu papel político no processo de democratização no Brasil estão relacionados a quatro fatores: a percepção dos índios sobre a necessidade de auto-organização voltada para a defesa de territórios, recursos naturais e autonomia política; o processo mais amplo de "redemocratização" da sociedade nacional, verificado nos anos 1980, que teve no processo constitucional de 1986-88 seu ponto alto; a crise do modelo tutelar gerido pelo Estado nacional; e o contexto transnacional (VERDUM, 2006).

Com relação ao contexto transnacional, o que se destaca é o discurso pelo desenvolvimento alicerçado por preocupações ecológicas do mundo todo, desde mudanças climáticas até o combate à pobreza.

Ouso do conceito etnodesenvolvimento, até início dos anos 1990, estava limitado a um restrito número de lideranças indígenas, Organizações Não Governamentais e intelectuais interessados no tema, porém, com o passar do tempo tornou-se parte integrante do vocabulário de um público mais diverso passando até mesmo a destacarse no discurso e na agenda das agências governamentais.

Ainda na década de 1990, o conceito Etnodesenvolvimento foi alentado por outro denominado "Desenvolvimento Sustentável", o qual se tornou popular a partir de 1992, através da Conferência Rio 92 das Nações Unidas.

\section{"Parênteses" para o Desenvolvi- mento Sustentável}

A expressão "Desenvolvimento Sustentável”, com o decorrer do tempo, devido a sua abertura a numerosas interpretações, foi cada vez mais utilizada por distintos atores sociais em posições institucionais, ideológicas e econômicas, também diferentes. 
Dentro dessas numerosas interpretações, é possível identificar uma, a qual assegura que o desenvolvimento sustentável está fundamentado na construção de problemas sociais e ambientais e é, atualmente, visualizado e, consequentemente transmitido, principalmente pela mídia, através de um ponto de vista catastrófico. Uma das representações desta interpretação, onde se criticam as "lentes catastrofistas", pode ser encontrada em Lomborg (2002), o qual afirma que atualmente temos mais tempo de lazer, maior segurança e menos acidentes, mais educação, mais comodidades, rendas maiores, menos fome, mais alimentos e uma vida mais longa e saudável. Nos países em desenvolvimento, muita gente ainda carece das necessidades básicas. Para essas pessoas, crescimento e desenvolvimento não são uma experiência inconsequente de flores artificiais, comida de microondas, álcool e drogas, mas uma chance de viver uma vida decente, com opções que transcendam a preocupação com a obtenção de comida suficiente.

Paralelamente, de acordo com Redclift (2002), as ligações entre o ambiente, a justiça social e a governabilidade têm se tornado crescentemente vagas em alguns discursos de sustentabilidade, e as relações estruturais entre o poder, a consciência e o meio ambiente têm sido, gradualmente, obscurecidas.

Ainda contando com grande alcance social, a noção de Desenvolvimento Sustentável evidencia um caráter polêmico e ambíguo, marcado por múltiplas e diversificadas interpretações e consensos apenas pontuais. A literatura que avalia seu significado e impacto social destaca suas positividades, suas contradições e os dilemas dos obstáculos existentes à sua evolução e consolidação como real alternativa de desenvolvimento social (MEDEIROS; ALMEIDA, 2010).

Análises que acentuam suas qualidades positivas destacam um caráter de inovação, uma forma alternativa à filosofia de desenvolvimento econômico, que substitui e supera um paradigma limitado, esgotado e ineficaz. O Desenvolvimento Sustentável pretende incorporar, também, uma perspectiva multidimensional, que articula economia, ecologia e política em uma visão integrada, e supera abordagens unilaterais e explicações reducionistas presentes nas propostas anteriores de desenvolvimento. Percebe-se, além disso, como pontos positivos desta noção, uma visão em longo prazo, em consonância com ciclos biofísicos e até mesmo com gerações futuras e envolvimento político do problema ecológico, o que substitui a visão meramente técnica, antes predominante.

Em contrapartida, a crítica à noção de sustentabilidade veiculada pelo relatório Brundtland condena que, ao permanecer obscuro seu significado, permite múltiplas leituras, que podem oscilar desde um significado avançado de desenvolvimento, associado à justiça social, participação política e preservação ecológica, até uma leitura conservadora que o torna semelhante ao conceito de crescimento econômico, ao qual se acrescentou uma variável ecológica.

Cabe também explorar a contradição semântica do termo, já que a associação das noções de sustentabilidade e desenvolvimento encerra um antagonismo de difícil solução. O termo sustentabilidade, advindo da ecologia, carrega o significado de tendência à estabilidade, equilíbrio dinâmico e interdependência entre ecossistemas, enquanto desenvolvimento diz respeito ao crescimento dos meios de produção, à acumulação e expansão das forças produtivas (MEDEIROS; ALMEIDA, 2010). 
Outra suscetibilidade à crítica é a tendência economicista do conceito, que supervaloriza a dimensão econômica do desenvolvimento em detrimento de seus aspectos éticos, culturais, sociais e políticos, embora, em teoria, privilegie uma perspectiva multidimensional.

Outro questionamento refere-se à possibilidade de sustentabilidade no contexto do capitalismo. Neste questionamento, é aberta uma fresta para argumentações de que o "novo conceito" tem sido difundido sem que se coloque, explicitamente, sua significação no cenário do capitalismo, e que ou ele mostra sua possibilidade de realização, ou cai no vazio.

Este debate abre espaço para a denominada "Justiça Ambiental", a qual se refere à busca do tratamento justo e do envolvimento significativo de todas as pessoas, independentemente de sua etnia, origem ou renda, no que diz respeito à elaboração, desenvolvimento, implementação e até mesmo reforço de políticas, leis e regulações ambientais. Por tratamento justo entende-se que nenhum grupo de pessoas deva suportar uma parcela desproporcional das consequências ambientais negativas resultantes de operações "desenvolvimentistas", bem como das consequências oriundas da ausência ou omissão de políticas que atendam às necessidades comuns.

De acordo com Acselrad (2004), as lutas por recursos ambientais são assim, simultaneamente, lutas por sentidos culturais, pois o meio ambiente é uma construção variável no tempo e no espaço, um recurso argumentativo a que atores sociais recorrem discursivamente através de estratégias e de afirmação de certos projetos em contextos de desigualdade sociopolítica.
Em meio a numerosas representações sociais e distintos interesses de grupos, cria-se uma dificuldade na possibilidade de consenso em torno do tema desenvolvimento sustentável, o que se apresenta como obstáculo ao exercício da "Justiça Ambiental".

Com objetivo de trazer a discussão para a aplicabilidade prática, como afirma Redclift (2002), desde a ECO-92, esses novos discursos ambientais refletem as mudanças da globalização, na genética e nas comunicações, e demonstram, vivamente, a importância das novas desigualdades espaciais, fazendo com que o global passe a ter sua importância associada ao local, fato que nos abre espaço para uma conversa sobre outro conceito: o Desenvolvimento Local.

\section{Autonomia e valorização do social - transformação consciente da realidade local?}

O Desenvolvimento Local aparece em cena como uma nova perspectiva que relativiza a autonomia do econômico em sociedades menos favorecidas, valorizando o social e as pessoas, procurando proporcionarlhes protagonismo no processo de desenvolvimento. As pessoas e comunidades locais são o espaço prioritário para o desenvolvimento em um exercício que obtém resultados através da participação e implicação das pessoas. O tipo de desenvolvimento que prevaleceu em regra geral, até o final de 1970, não possuía como preocupação limites ecológico para a obtenção do crescimento econômico, ignorando assim, os riscos de degradação da natureza e a limitação dos elementos naturais.

O surgimento e o avanço do "Desenvolvimento Local" significaram um turning point para a concepção do termo 
"desenvolvimento". Sua proposta de abarcar preocupações acerca do meio ambiente numa dupla perspectiva, primeiro, como sustentabilidade do desenvolvimento e, numa etapa posterior, como recurso a favor do próprio desenvolvimento, fez com que novos paradigmas fossem trazidos à tona na busca de novas interpretações e operacionalizações para tal expressão.

Amaro (1993) considera o

Desenvolvimento Local como um processo de transformação, mudança que recusa a conservação. É centrado numa comunidade, isto é, o ponto de partida de referência é a própria comunidade local. O local enquanto resultado de uma construção de identidades — um conjunto de interesses que se identifica e assume onde são mobilizáveis ações de solidariedade concretas.

O mesmo autor apresenta diversos elementos para poder falar-se sobre Desenvolvimento Local (DL), considerando-o como,

Parte da existência de necessidades não satisfeitas a que se procura responder a partir das capacidades locais, mas também recorrendo a recursos exógenos, como forma de fertilização mútua, onde estes e aqueles aprendem mutuamente. Assume uma lógica integrada, onde a intervenção não se restringe a problemas focalizados (por exemplo, desemprego, saúde, idosos, etc.), mas sim ao conjunto de problemáticas que se interligam. Tudo tem a ver com tudo. Foca-se no trabalho em parceria, a partir de definição de ações conjuntas, a cooperação, a negociação dos conflitos e das solidariedades locais. O impacto por toda a comunidade, isto é, exerce um efeito de exemplificação para toda a comunidade. $\mathrm{E}$ atua segundo uma diversidade de caminhos. (AMARO,1993, p.16).

O conceito de desenvolvimento local vem sendo criticado e renovado por muitos autores ao longo dos anos. Um marco importante passa a ser, em 1990, o relatório mundial do Programa das Nações Unidas para o Desenvolvimento (PNUD). Este relatório coloca que o índice de desenvolvimento humano (IDH) tende a relativizar o Produto Nacional Bruto (PNB) por habitante, enquanto medida universal do desenvolvimento, e tem forte significado simbólico.

O desenvolvimento passa, então, a ser entendido levando-se em conta os aspectos locais, aspectos estes que têm significado em um território específico. O global passa a ter sua importância associada ao local, considerando-se o contrário também válido, já que um está em constante transformação por conta das interferências do outro e, devido a isto, diversos autores utilizam o termo "glocal", a junção dos dois aspectos, para se referir ao desenvolvimento.

Alguns autores já tentaram desconstruir o termo desenvolvimento por considerarem que este implica práticas associadas à colonização, à ocidentalização do mundo, à globalização econômico-financeira e à uniformização planetária. Isso foi discutido em 2002, em um colóquio internacional organizado na UNESCO, "apesar de não explicarem como substituir o conceito e a prática do desenvolvimento, sobretudo nos contextos em que as desigualdades e as carências são ainda muito flagrantes" (MILANI, 2005, p.10).

Atualmente, é quase unânime entender que o desenvolvimento local não está relacionado unicamente com crescimento econômico, mas também com a melhoria da qualidade de vida das pessoas e com a conservação do meio ambiente. Estes três fatores estão inter-relacionados e são interdependentes: econômico, ambiental e social. 
O Desenvolvimento Local pressupõe uma transformação consciente da realidade local. Isto implica uma preocupação não apenas com a geração presente, mas também com as gerações futuras, e é neste aspecto que o fator ambiental assume fundamental importância. Sachs (2001) afirma que o desgaste ambiental pode não interferir diretamente na geração atual, mas pode comprometer sobremaneira as próximas gerações.

Quando se trata de interpretar essas nomenclaturas, seus significados se confundem e levam-nos a pensar, afinal, a que conceito estamos nos referindo: Desenvolvimento sustentável, Desenvolvimento Local ou ainda Etnodesenvolvimento?

Evidenciar o esforço envolvido em diferenciar o modo de operacionalizar tais conceitos talvez seja a chave para uma resposta. É através dessa ótica que terá enfoque, a seguir, a proposta do construto Etnodesenvolvimento.

\section{O Local, a Sustentabilidade e o Et- nodesenvolvimento - Paralelismos e incongruências}

De acordo com Little (2002), o foco central de quaisquer programas ou atividades que visam ao etnodesenvolvimento é o grupo étnico e suas necessidades econômicas e reivindicações políticas. Para tanto, o principal nível no qual se trabalha o Etnodesenvolvimento é o local, justamente porque é nesse nível que existem maiores oportunidades para os grupos étnicos exercerem influência nas decisões que thes afetam e, como consequência, promover mudanças nas suas práticas econômicas e sociais.

Podemos identificar a existência de duas forças em constante tensão na implementação de processos de etnodesenvolvimento local: por um lado, a construção política da "autonomia cultural" por parte do grupo étnico frente ao Estado nacional; e, por outro, a operacionalização de formas de integração desse mesmo grupo étnico nas estruturas da economia nacional e internacional. A meta da autonomia cultural compõe o guia principal para o estabelecimento das condições necessárias para a implementação do etnodesenvolvimento (LITLLE, 2002).

A autonomia cultural incide, entre inúmeras coisas, na elaboração de práticas produtivas que garantem o abastecimento das suas necessidades básicas bem como permite a produção de excedentes a serem utilizadas na geração de renda para a compra de produtos industrializados. A elaboração dessas práticas baseia-se em conhecimentos da etnoecologia, já que as relações ecológicas existentes, tomadas no seu conjunto, mostram os caminhos da sustentabilidade ambiental, o que serve como base para um plano de Etnodesenvolvimento (TOLEDO, 1992).

Já para Grünewald (2003), sustentabilidade ambiental e Etnodesenvolvimento (termo que reserva para o desenvolvimento sustentável de uma comunidade étnica quando aliado ao revigoramento do seu patrimônio cultural e consequente fortalecimento de sua identidade étnica, isto é, à sua etnicidade - sustentando a etnia a determinação étnica) são coisas bem diferentes. Se a etnicidade pode ser algo bem mais abrangente que $o$ desenvolvimento sustentável, a questão da sustentabilidade, paradoxalmente, pode ser mais ampla do que o espaço reduzido de promoção de etnodesenvolvimento (pois não é em todos os espaços sociais de uma aldeia que se promove processo de etnodesenvolvimento). 
Stavenhagen apud Azanha (2002) afirma que o Etnodesenvolvimento teria como princípios básicos objetivar a satisfação de necessidades básicas do maior número de pessoas, ao invés de priorizar o crescimento econômico; embutir-se de visão endógena, ou seja, dar resposta prioritária à resolução dos problemas e necessidades locais na busca da solução dos problemas; preocupar-se em manter a relação equilibrada com o meio ambiente; e visar à auto-sustentação e à independência dos recursos técnicos e de pessoal a proceder a uma ação integral de base, com atividades mais participativas.

Através de artigos que reúnem esforços para pensar o planejamento de novos modelos de intervenção indigenista aliado à ideia de fomento ao Etnodesenvolvimento, Lima e Barroso-Hoffmann apontam:

Ao tomar a perspectiva do etnodesenvolvimento, os trabalhos não apenas partem da ideia de que as sociedades indígenas podem garantir sua especificidade e autonomia perante o 'mundo dos brancos', como também supões certos padrões étco-morais sobre os modos como o 'mundo dos brancos' se posicionará em relação à vida desses grupos diferenciados, levantando, entre outras questões, as de quais valores serão acionados, que tipo de alianças esses valores embasarão e com que setores, sob que formatos jurídicos e a partir de que graus de flexibilização por parte do Estado brasileiro em face da ordem econômica globalizada essas alianças serão mais viáveis. (LIMA; BARROSOHOFFMANN, 2002, p.19).

É possível verificar, no trecho, a atribuição de ênfase política na noção de etnodesenvolvimento e ainda, o uso da perspectiva do etnodesenvolvimento serve para pensar uma nova relação entre diferentes, tornando-se fundamental a construção de instrumentos que localizem as áreas que melhor asseguram o direito à diferença e se prestam à troca de saberes e de bens entre as sociedades indígenas, os segmentos sociais dominantes e a administração indigenista (LIMA; BARROSO-HOFFMANN, 2002).

Não se pode negar que o Etnodesenvolvimento é uma perspectiva intimamente ligada à administração de políticas públicas, porém, fica clara a necessidade de se considerarem incluídos a tal construto, aspectos econômicos e culturais.

O Etnodesenvolvimento se remete a um processo que visa à manutenção e à transformação de uma sociedade ligada a determinadas configurações produtivas locais, dependentes diretamente ou não de relações globais.

É importante ressaltar que a proposta de Etnodesenvolvimento prevê liberdade à população local de receber ou não influências exógenas por parte de órgãos e setores mediadores e intervencionistas. São justamente projetos que levem em conta a flexibilidade estrutural e histórica do desenvolvimento que devem ser preconizados como viáveis em longo prazo. Além disso, existem especificidades para as comunidades locais, e o etnodesenvolvimento tem que partir das tendências dessas comunidades e até colocar ideias novas, tanto para o desenvolvimento quanto para tentativas de resolução de problemas. Além do desenvolvimento sustentável, acrescenta -se à noção de etnodesenvolvimento, a administração do Território.

Ligada à questão indígena, segundo Gallois (2001), as duas principais demandas em relação ao desenvolvimento são: o direito e o controle sobre suas terras e o reconhecimento à sua capacidade de autodeterminação. 
Nesse sentido, a mesma autora critica a existência, até hoje, de um estereótipo do que é ser índio. Isso fere diretamente o direito à autodeterminação e legitima a ideia de cultura como algo imutável, resultando em preconceito aos indígenas, por serem considerados "aculturados", até mesmo quando se trata de suas práticas agrícolas e seu envolvimento com o ambiente.

Em alguns momentos, os representantes indígenas transferem para segundo plano a questão da conservação da natureza, visto que tais medidas se enquadram em uma reavaliação dos impactos do desenvolvimento causado pela sociedade ocidental, não por eles. Atribuir aos indígenas, bem como a populações locais em geral, funções conservacionistas, o que muitas vezes remete ao uso "tradicional" das terras, acaba se transformando em um discurso muito distante da realidade, no passo que tradição e modernidade presentes no dia-a-dia dessas populações, constantemente passam por processos de ressignificação.

Lima e Barroso-Hoffmann (2002) chamam atenção a essa questão, na medida em que se faz uso da sustentabilidade ambiental, relacionada às comunidades tradicionais, como simples argumento político, o qual acaba por não contemplar as populações locais em si, quem mais deveria.

De acordo com Oliveira (2000),

A proposta de etnodesenvolvimento já está a indicar que a participação da população alvo nas diferentes etapas do processo de etnodesenvolvimento é condição de sua exequibilidade, portanto, parece ficar evidente que isso implica o reconhecimento de uma comunidade de comunicação de natureza interétnica. Implica igualmente que subjacente ao conceito de etnodesenvolvimento está uma comunidade de argumentação.
Não se trata de uma comunidade de argumentação interpares, porém entre grupos e indivíduos portadores de culturas distintas, como ocorre tipicamente nas relações interétnicas. Desde logo, em lugar de confronto étnico - algo corrente nos programas desenvolvimentistas - haveria de se esperar um encontro entre interlocutores imbuídos menos de verdades e mais de pontos de vista. (OLIVEIRA, 2000, p.218).

\section{Algumas considerações}

É possível identificar que o etnodesenvolvimento, embora não deixe de se constituir em uma estratégia de mudança social induzida, é realizado em condições bem diversas àquelas que sustentariam os projetos tradicionais desenvolvimentistas.

Grandiosos problemas revelam, pouco a pouco, a necessidade de o campo técnico e científico assumirem o diálogo interétnico e intercultural como fator decisivo na construção de uma forma alternativa de desenvolvimento, não podendo diminuir a significância das dificuldades imbricadas à implementação desse mesmo diálogo, reconhecendo que, sob a dimensão política, além da democratização, haveria também de invocar a questão da eticidade, onde predomina a ética do discurso.

Assim, a prática de elaboração e aplicação de políticas públicas podem ser simultaneamente críticas e autocríticas, desde que baseadas no reconhecimento da importância do diálogo interétnico, contribuindo para melhoria das condições de vida das populações locais, bem como para que o Estado atenda aos preceitos de moralidade na condução da comunicação entre cientistas, técnicos e populações locais. 
A mudança dos antigos padrões de desenvolvimento (alicerçados puramente em crescimento econômico) e de sistemas de produção de baixa sustentabilidade econômica, social, cultural e ambiental implica não somente a busca de maior racionalização produtiva com base nas especificidades de cada localidade, mas também uma mudança nas atitudes e valores dos atores sociais em relação ao manejo e conservação dos recursos. Esta mudança dependerá, inclusive, da habilidade dos movimentos sociais, em seu sentido mais amplo, de atrair forças, de estabelecer alianças e de liderar um processo que torne o ideal da sustentabilidade uma alternativa real de desenvolvimento social.

Em meio a essas elucidações, verifica-se que os pilares da perspectiva Etnodesenvolvimento ainda se encontram em processo dinâmico de construção para operacionalização do termo, fazendo com que se abram muitos espaços para novos estudos e inovações de conceito a cada momento. Porém, cabe aqui uma questão para reflexão, referindo-nos a termos procedentes de processos dinâmicos que se transformam a cada situação, seriam tais termos possíveis de conceituação?

\section{Para saber mais sobre...}

...Alguns aspectos de idéias antropológicas que são absorvidas e expandidas a partir do Serviço de proteção ao índio da década de 1950, ver SOUZA LIMA, Antonio Carlos de. "A 'identificação' como categoria histórica”. In: OLIVEIRA, João Pacheco de (org.). Indigenismo e territorialização: poderes, rotinas e saberes coloniais no Brasil contemporâneo. Rio de Janeiro, Contra Capa Livraria, 1998, e
SOUZA LIMA, Antonio Carlos de. 2000. "L'indigenisme au Brésil: migration et reappropriations d'un savoir adminstratif". Révue de Synthèse, juillet-décembre, t. 121, 4s. (3-4), pp. 381-410.

...A abordagem de Fredrik Barth para o problema da etnicidade com base em uma análise de sua obra, levando-se em conta o poder explicativo dos fatores ecológicos e demográficos em seu modelo, a importância de sua tese da identidade relativa, a genealogia das influências teóricas encontradas nas explicações barthianas e o problema do ator racional como fio condutor de sua concepção interacionista das relações sociais, ler VILLAR, Diego. Uma abordagem crítica do conceito de "etnicidade" na obra de Fredrik Barth. In Mana, 10 (1):165-192, 2004. Disponível em:

http://www.scielo.br/scielo.php?p $\mathrm{id}=\mathrm{S} 010493132004000100006 \& \mathrm{script}=\mathrm{s}$ ci_abstract\&tlng=en.

E ainda, sobre Raça e Etnia, e a problematização do processo de autoconstituição de grupos sociais e culturais diferenciados (etnogênese), consultar ARRUTI, José Maurício Andion. A emergência dos "remanescentes" notas para o diálogo entre indígenas e quilombolas. In Mana, 3(2):7-38, 1997. Disponível em: http://www.scielo.br/scielo.php?script=sci_ar ttext\&pid=S010493131997000200001\&lng $=$ pt\&nrm=iso\&tlng=pt.

...Surgimento e funcionamento dos mecanismos de fomento ao desenvolvimento indígena: os Projetos Demonstrativos (PDA) e os Projetos Demonstrativos dos Povos Indígenas (PDPI) ler VERDUM, Ricardo. Etnodesenvolvimento e mecanismos de fomento do desenvolvimento dos povos 
indígenas: a contribuição do subprograma Projetos Demonstrativos. (PDA). In: LIMA, A. C. S. \& BARROSO-HOFFMANN, M. (Orgs.). Etnodesenvolvimento e políticas públicas: bases para uma nova política indigenista. Rio de Janeiro: Contracapa/ LACED, 2002. p. 87-105.

...Multiculturalismo, diferentes culturas (provenientes de diferentes sociedades) que interpretam de diferentes formas (culturais) a natureza, bem como a imbricação sociedadenatureza ou cultura-natureza relacionada ao construto do etnodesenvolvimento ler LATOUR, B. Jamais fomos modernos: ensaio de antropologia simétrica. Traduzido por Carlos Irineu da Costa. Rio de Janeiro: Editora 34, 1994. 152 p. (Coleção TRANS).

...Comunidades tradicionais verificar SANTILLI,Juliana. Populações tradicionais: a construção de um conceito jurídico. In: Socioambientalismo e novos direitos: proteção jurídica à diversidade biológica e cultural. São Paulo: Peirópolis, 2005. p. 123-134. E, SPAREMBERG, Raquel Fabiana Lopes; KRETZMANN, Carolina Giordani. Antropologia, multiculturalismo e Direito: o reconhecimento da identidade das comunidades tradicionais no Brasil. In: COLAÇO, Thais Luzia. (Org.). Elementos de Antropologia Jurídica. Florianópolis: Conceito Editorial, 2008. p. 93-124.

...Territorialidade das Comunidades Tradicionais ler BERTHO, Ângela Maria de Moraes. Territorialidade em transformação. In: Os índios guaranis da Serra do Tabuleiro e a conservação da natureza. (Uma perspectiva etnoambiental). Florianópolis. Tese. (Doutorado Interdisciplinar em Ciências Humanas - Área Temática Sociedade e
Meio Ambiente) Universidade Federal de Santa Catarina, 2005. p. 31-90; EVANSPRITCHARD, E. E. Tempo e espaço. In: Os nuer. São Paulo: Perspectiva, 1993.p. 107150; FRAXE, Therezinha de Jesus Pinto et. al. Natureza e mundo vivido: o espaço e lugar na percepção da família cabocla/ribeirinha. In: SCHERER, Elenise; OLIVEIRA, José Ademir de. (Org.). Amazônia: políticas públicas e diversidade cultural. Rio de Janeiro: Garamond, 2006. p. 233-258; RAMOS, Alcida Rita. Espaço Sanumá. In: Memórias Sanumá: espaço e tempo em uma sociedade Yanomami. Brasília: UNB, 1990.p. 25-37; RAMOS, Alcida Rita. A importância do território. In: Sociedades indígenas. 2. ed. São Paulo: Ática, 1988. p. 13-22.

...A problemática do etnodesenvolvimento dentro dos contextos ainda maiores do desenvolvimento econômico no mundo contemporâneo e do respeito à diversidade cultural dentro dos Estados nacionais atuais, utilizando-se como referencial geográfico principal os países latino-americanos, dando ênfase no caso específico do Brasil ler LITTLE, Paul E. Etnodesenvolvimento: autonomia cultural na era do liberalismo global. In: Revista Tellus. Ano 2, n. 3, out.2002. Campo Grande: UCDB, p. 33 - 52.

...As limitações e contradições acerca do conceito etnodesenvolvimento consultar GALLOIS, Dominique Tilkin. Sociedades Indígenas e Desenvolvimento: discursos e práticas, para pensar a tolerância. In: GRUPIONI, Luís Donisete Benzi; VIDAL, Lux; FISCHMANN, Roseli (Org.). Povos Indígenas e Tolerância: construindo práticas de respeito e solidariedade. São Paulo: Universidade de São Paulo, 2001,p.167-188. 


\section{Referências}

ACSELRAD, H. As práticas espaciais e o campo dos conflitos ambientais. In: ACSELRAD, H. (org.). Conflitos ambientais no Brasil. Rio de Janeiro: Relume-Dumará, 2004. p.13-35.

AMARO, R. As Novas Oportunidades de Desenvolvimento Local. In: A Rede para o Desenvolvimento Local, n. 8. Faro: IN LOCO. p. 16-22, 1993.

AZANHA, G. Etnodesenvolvimento, mercado e mecanismos de fomento: possibilidades de desenvolvimento sustentado para as sociedades indígenas no Brasil. In: LIMA, $A>C>S$; BARROSO-HOFFMANN, M. (org). Etnodesenvolvimento e Políticas Públicas: bases para uma nova política indigenista. Rio de Janeiro: Contra Capa Livraria, 2002.p.29-37.

GALLOIS, D. T. Sociedades Indígenas e Desenvolvimento: discursos e práticas, para pensar a tolerância. In: GRUPIONI, Luís Donisete Benzi; VIDAL, Lux; FISCHMANN, Roseli (Org.). Povos Indígenas e Tolerância: construindo práticas de respeito e solidariedade. São Paulo: Universidade de São Paulo, 2001. p. 167-188.

GRÜNEWALD, R. A. Etnodesenvolvimento indígena no Nordeste (e Leste): aspectos gerais e específicos. Revista AntHropológicas, Recife, v.14, n. 1 e 2, p. 47-31, 2003.

LIMA, A. C. S., BARROSO-HOFFMANN, M. Questões para uma política indigenista: etnodesenvolvimento e políticas públicas. Uma apresentação. In: LIMA, A. C. S. \& BARROSO-HOFFMANN, M. (Org.). Etnodesenvolvimento e políticas públicas: bases para uma nova política indigenista. Rio de Janeiro: Contracapa/ LACED, 2002. p. 07-28.

LITTLE, P. E. Etnodesenvolvimento: autonomia cultural na era do liberalismo global. Revista Tellus. Campo Grande: UCD, ano 2, n. 3, out.2002, p. 33 - 52, 2002.

LOMBORG, B. Catástrofe ou progresso? In: LOMBORG, Bjorn. O ambientalista cético. Rio de Janeiro: Campus, 2002, p. 393-422.

MEDEIROS, M., ALMEIDA, J. Insustentável sustentabilidade do desenvolvimento? Revista Uniara, Araraquara, p. 107-114, v. 13 n.1, 2010.

MILANI, C. Teorias do Capital Social e Desenvolvimento Local: lições a partir da experiência de Pintadas (Bahia, Brasil). In: Capital social, participação política e desenvolvimento local: atores da sociedade civil e políticas de desenvolvimento local na Bahia. Escola de Administração da UFBA (NPGA/NEPOL/PDGS), 2005.

OLIVEIRA, R. C. O. Ação indigenista, etnicidade e o diálogo interétnico. Estudos Avançados, v. 14, n. 40, sep./dec. 2000.

REDCLIFT,M. R. Pós-sustentabilidade e os novos discursos de sustentabilidade. Raízes, Campina Grande, v. 21, n. 1, 2002, p. 124-136. 
SACHS, I. Das coisas e dos homens: Teoria do Desenvolvimento a espera de sua revolução copernicana. Jornal da Ciência (JC E-Mail) - Noticias de C\&T - Serviço da SBPC, no. 1836. São Paulo, 23 de julho de 2001.

VERDUM, R. Etnodesenvolvimento e mecanismos de fomento do desenvolvimento dos povos indígenas: a contribuição do subprograma Projetos Demonstrativos. (PDA). In: LIMA, A. C. S. \& BARROSO-HOFFMANN, M. (Org.). Etnodesenvolvimento e políticas públicas: bases para uma nova política indigenista. Rio de Janeiro: Contracapa/ LACED, 2002. p. 87-105.

VERDUM, R. Etnodesenvolvimento: nova/velha utopia do indigenismo. 2006. 190f. Tese (doutorado em Ciências Sociais) - Centro de Pesquisas e Pós-Graduação sobre as Américas, Universidade de Brasília, Brasília, 2006.

STAVENHAGEN, R. Etnodesenvolvimento: uma dimensão ignorada no pensamento desenvolvimentista. Anuário Antropológico, v. 84, p.11-44, 1985.

TOLEDO, V. What is ethnoecology? Origins, scope and implications of a rising discipline. Etnoecológica1, v.1, n.1, p. 5-21, 1992. 